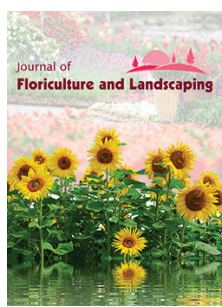

ISSN: $2663-6050$

Received: August 09, 2019 Accepted: March 08, 2020 Published: March 30, 2020

*Corresponding Author: Dhanasekaran Dhanraj Email: dhansflora@gmail.com

\section{Performance of foliage ornamentals in hydroponic nutrient solutions}

\author{
Dhanasekaran Dhanraj* \\ Department of Horticulture, Faculty of Agriculture, Annamalai University, Annamalai nagar-608002, Tamil Nadu, India
}

\begin{abstract}
Vertical garden is one of the approach of green building envelope with green facades and green living walls creates a richer ecosystem, enhances biodiversity, improves mental health, alleviates environmental externalization generated by urban areas (Pollution, runoff and heat island effect etc). However, the limitations of vertical gardening system are the choice of plants and the module of growing. Numerous exotic and native ornamentals are suggested for vertical systems based on the requirements. Selection of plants grown under indoor environments with limited space is narrowing down the choice of ornamental flora. On the other hand hydroponics is an alternative sustainable production system under conditions in which resources are limited. Hydroponics is a very young science which has commercial basis during recent days. However, even in relative short period of time it has been adapted in many situations from outdoor to indoor for growing various crops. Hence, an experiment was conducted with Hoagland \& Arnon solution (1938), Cooper's solution (1979), Saparamadu's solution (2010) and Mattson and Peters solution (2014) and a control with Irrigation water to study the rooting behavior of five plants viz., Devil's ivy (Epipremunm aureum), Wandering jew (Zebrina pendula), Arrowhead plant (Syngonium podophyllum), Philodendron (Philodendron erubescens), Boat lily (Tradescantia spathacea) under passive hydroponic vertical garden module. The $\mathrm{pH}$ was monitored for acidity and basicity range and $\mathrm{EC}$ were monitored for salt concentration in all the nutrient solution periodically. Observation on root parameters viz., Number of roots plant $-^{1}$, Root length $(\mathrm{cm})$ and Root weight $\left(\mathrm{g} \mathrm{plant}^{-1}\right)$ were observed at 30, 60 and 90 days after planting. Results of the experiment revealed that number of roots, root length and root weight exerted maximum values in those plants grown under $\mathrm{T}_{3}$ (Cooper's solution). Minimum rooting with lowest weight was recorded in $\mathrm{T}_{4}$ (Saparamadu solution) in all the stages of observation in devil's ivy. Whereas in other four ornamentals viz., Wandering jew (Zebrina pendula), Arrowhead plant (Syngonium podophyllum), Philodendron (Philodendron erubescens) and Boat lily (Tradescantia spathacea) recorded lowest root parameters in $\mathrm{T}_{1}$ (Irrigation water) under 30 days of observation and at 60 and 90 days minimum number of roots, root length and root weight was recorded under $\mathrm{T}_{4}$ (Saparamadu solution).
\end{abstract}

KEYWORDS: Hydroponics, Nutrient solution, Foliage ornamentals, Vertical module

\section{INTRODUCTION}

Due to rapid increase in population explosion the per capita availability of living space is declining which is considered as a major issue in urban communities. Therefore, the challenge for the urban landscape designers is to create landscape within limited space considering the ecological and environmental impacts. The most critical changes in the world over the last century have been derived from the variety of environmental problems. Unfortunately, in many past situations environmental effects were ignored during the urban designing. In recent decades ecological design has been applied to an increasingly diverse range of technologies and innovative solutions for the management of resources. Ecological technologies have been created for architecture and landscape design especially in the field of environmental protection and restoration. In this context, landscape design has a crucial role to play in achieving ecological perspectives in design, execution and maintenance of green environment with limited resources. Vertical garden is one of the approach of green building envelope with green facades and green living walls creates a richer ecosystem, enhances biodiversity, improves mental health, alleviates environmental externalization generated by urban areas (Pollution, runoff and heat island effect etc). However, the limitations of vertical gardening system are the choice of plants and the module of growing. Numerous exotic and native ornamentals are suggested for vertical systems based on the requirements. Selection of plants grown under indoor environments with limited space is narrowing down the choice of ornamental flora. To be grown under urban minimal spaces, foliage ornamentals are the best option among the softscape components in ornamental industry.

On the other hand hydroponics is an alternative sustainable production system under conditions in which resources are limited. Hydroponics is a very young science which has commercial basis during recent days. However, even in relative short period of time it has been adapted in many situations

Copyright: ๑ The authors. This article is open access and licensed under the terms of the Creative Commons Attribution License (http://creativecommons.org/licenses/by/4.0/) which permits unrestricted, use, distribution and reproduction in any medium, or format for any purpose, even commercially provided the work is properly cited. Attribution - You must give appropriate credit, provide a link to the license, and indicate if changes were made. 
from outdoor to indoor for growing various crops. Hydroponic crop production has significantly increased in recent years worldwide as it allows a more efficient use of water and nutrients as well as better climate control. Further, the crops grown under hydroponic culture are of good quality with increased productivity. Among the various factors affecting hydroponic production systems, the nutrient solution is considered to be one of the most important determining factors of crop growth and production. An ideal nutrient solution should satisfy Arnon's criteria of essentiality in adequate quantity and in available forms, in addition to proper physiochemical conditions i.e. aeration, $\mathrm{pH}$ and EC suitable for crop growth. Further, in passive hydroponic systems which are convenient for growing ornamental plants in urban space, the nutrient solution is playing vital role as the solution is maintained without changing (or) circulation for a period of more than two weeks. Over continuous maintenance of the a plant in same solution for two weeks leads to drastic changes in dissolved oxygen content, $\mathrm{EC}$ and $\mathrm{pH}$ of the nutrient solution and there by affects the plant growth. For development of a passive hydroponic system to grow ornamental plants in indoor condition it is important to identify suitable plants and appropriate nutrient solution to boost the growth and ornamental value of the plants. Hence, in this present experiment five foliage ornamentals were selected to grow under various nutrient solutions under passive hydroponic systems.

\section{MATERIALS AND METHODS}

The present experiment was carried out in the Department of Horticulture, Faculty of Agriculture, Annamalai University, Annamalai Nagar and Tamil Nadu during 2017- 2019 with four different nutrient formulations viz., Hoagland \& Arnon solution (1938), Cooper's solution (1979), Saparamadu's solution (2010) and Mattson and Peters solution (2014) and a control with Irrigation water for growing foliage ornamentals under passive hydroponic vertical garden module with four replications in completely randomized block design. The $\mathrm{pH}$ was monitored for acidity and basicity range and $\mathrm{EC}$ were monitored for salt concentration in all the nutrient solution periodically. The following five plants viz., Devil's ivy (Epipremunm aureum), Wandering jew (Zebrina pendula), Arrowhead plant (Syngonium podophyllum), Philodendron (Philodendron erubescens), Boat lily (Tradescantia spathacea) were chosen for the experiment. The experiment unit was designed out in 62" X 2.5". PVC pipe closed at both ends. The pipes were fitted with a drainage outlet and slots of 1.5" were made at the top to accommodate five plants and the plants were grown in 2" net pots. The entire experiment set up was fabricated in an angular iron rod with 5 layers of PVC pipes for five treatments at different heights. All the pipes will be filled with 5 litres of four different nutrient solutions, viz., T2 - Hoagland \& Arnon (1938), T3-Cooper's (1979), T4-Saparamadu (2010),T5Mattson and Peters (2015) and irrigation water as control (T1).

Three plants were selected at random from each treatment and tagged for the recording various biometric observations in all the treatments. Observation on root parameters viz., Number of roots plant $-^{1}$, Root length $(\mathrm{cm})$ and Root weight $\left(\right.$ g plant $\left.^{-1}\right)$ were observed at 30, 60 and 90 days after planting.

\section{RESULTS AND DISCUSSION}

Plants grown in soil and hydroponics have the same requirements for water, oxygen and nutrients, but the frequent rate of replenishment of these in soilless culture is one of the main advantages of hydroponic production. In most soil systems, plant roots have the freedom to grow and stretch out as they needed. Many plants will send tap roots and some of them feet deep into the soil in search of nutrients and water, while other species may develop shallow, but highly branched root systems. In hydroponics, root volume is considered as an important factor as they absorb water, nutrients and oxygen directly by the root surface on a frequent basis and hydroponic plants don't need to expend as much energy for long-distance foraging. By increasing root density, new roots will be produced. The regeneration of new roots is essential for normal plant development, as the majority of nutrients are absorbed through younger root tissues. In this present experiment, more number of roots $(53.42,230.25$ and 345.41 in Devil's ivy, 42.23, 55.06 and 70.42 in Wandering jew, 230.18, 266.97 and 281.18 in Arrowhead plant, 72.36, 101.63 and 146.28 in Philodendron and 29.18, 41.28, 69.3 roots in Boat lily) was recorded in the treatment $\mathrm{T}_{3}$ (Cooper's solution) in all the three stages i.e. 30, 60 and 90 days of observations respectively (Table 1 ).

Interestingly, the minimum number of roots $(28.31,78.53$ and 128.55 at 30,60 and 90 days of observations respectively) was observed under the treatment $\mathrm{T}_{4}$ (Saparamadu solution) in Devil's ivy in all the three stages of observations. In contrast with the above result, minimum number of roots (30.43 in Wandering jew, 78.36 in Arrowhead plant, 32.19 in Philodendron and 15.62 in Boat lily) was recorded in $\mathrm{T}_{1}$ (Irrigation water) at 30 days of observation. However, at 60 and 90 days of observation, minimum number of roots (38.34 and 38.66 in Wandering jew, 94.18 and 97.23 in Arrowhead plant, 54.28 and 50.73 in Philodendron and 21.42 and 23.68 in Boat lily) was observed in those plants grown under $\mathrm{T}_{4}$ (Saparamadu solution).

The data on root length also exerted similar results in producing the lengthy root $(21.52 \mathrm{~cm}, 31.45 \mathrm{~cm}$ and $49.13 \mathrm{~cm}$ in Devil's ivy, $23.36 \mathrm{~cm}, 32.11 \mathrm{~cm}$ and $49.56 \mathrm{~cm}$ in Wandering jew, $17.29 \mathrm{~cm}$, $25.64 \mathrm{~cm}$ and $33.32 \mathrm{~cm}$ in Arrowhead plant, $15.69 \mathrm{~cm}, 36.78 \mathrm{~cm}$ and $62.76 \mathrm{~cm}$ in Philodendron and $10.68 \mathrm{~cm}, 17.86 \mathrm{~cm}$ and 25.68 in Boat lily) in the treatment $\mathrm{T}_{3}$ (Cooper's solution) in 30, 60 and 90 days of observations. However, the shortest root in Devil's ivy was observed in $\mathrm{T}_{1}$ (Irrigation water) which recorded $12.51 \mathrm{~cm}$, $23.52 \mathrm{~cm}$ and $36.54 \mathrm{~cm}$ at 30,60 and 90 days of observations respectively. As like the number of roots, the other four foliage ornamentals showed similar results for 30 days of observations for minimum root length $(13.16 \mathrm{~cm}, 8.01 \mathrm{~cm}, 10.31 \mathrm{~cm}$ and $4.28 \mathrm{~cm}$ at 30,60 and 90 days of observation respectively) under the treatment $\mathrm{T}_{1}$ (Irrigation water) in Wandering jew, Arrowhead plant, Philodendron and Boat lily respectively. However, during 60 and 90 days of observations the treatment $\mathrm{T}_{4}$ (Saparamadu solution) recorded the minimum root length of $618.34 \mathrm{~cm}$ and $19.69 \mathrm{~cm}$ in Wandering jew, $15.68 \mathrm{~cm}$ and $16.72 \mathrm{~cm}$ in arrow head plant, $14.68 \mathrm{~cm}$ and $19.55 \mathrm{~cm}$ in philodendron and $7.98 \mathrm{~cm}$ and $9.36 \mathrm{~cm}$ in Boat lily respectively (Table 2 ). 

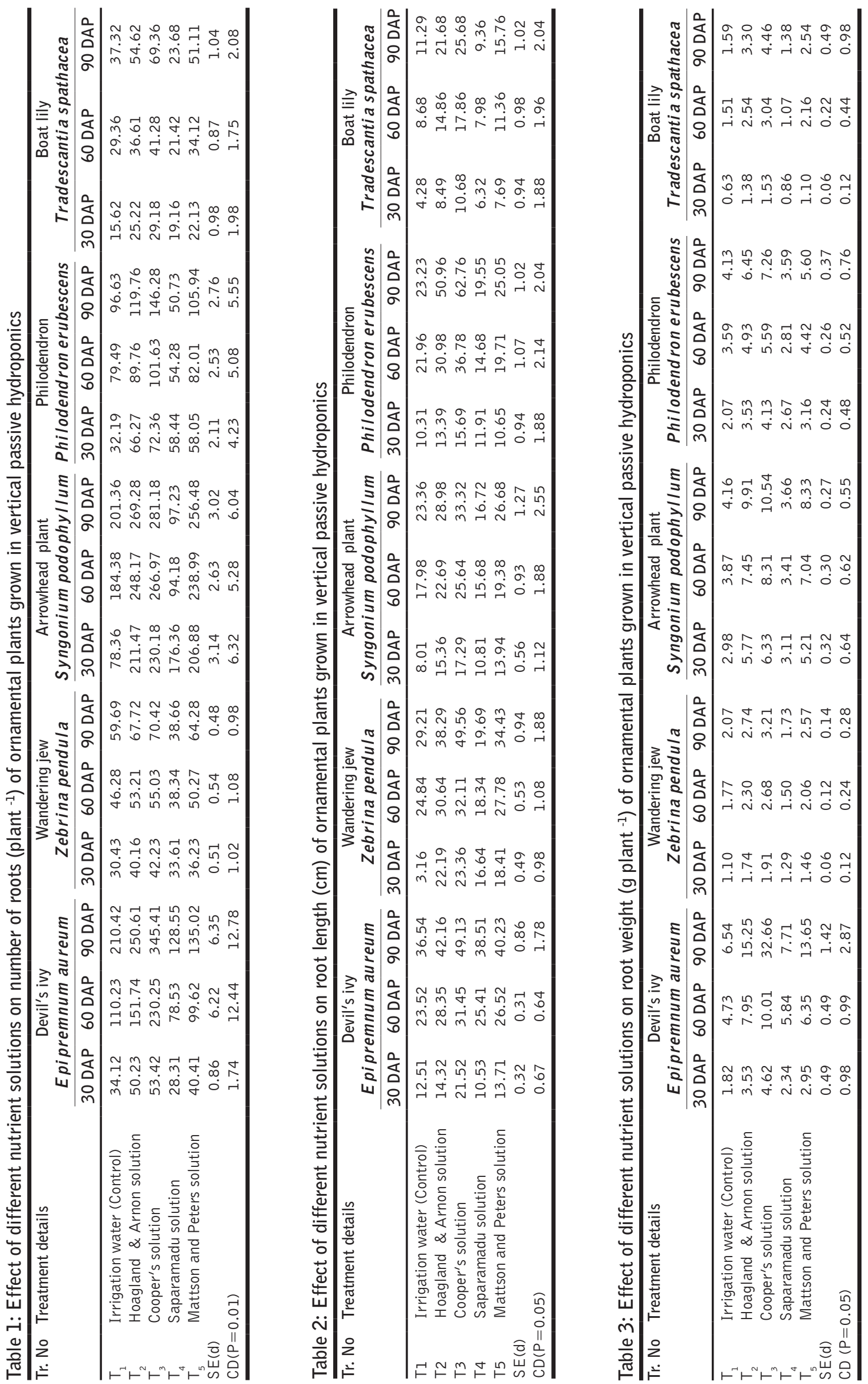
Among the different nutrient solutions, plants grown under the treatment $\mathrm{T}_{3}$ (Cooper's solution) produced maximum root weight (4.62 $\mathrm{g} \mathrm{plant}^{-1}, 10.01 \mathrm{~g}$ plant $^{-1}$ and $32.66 \mathrm{~g} \mathrm{plant}^{-1}$ in Devil's ivy, 1.91 g plant $^{-1}, 2.68$ g plant $^{-1}$ and 3.21 g plant $^{-1}$ in Wandering jew, 6.33 g plant $^{-1}, 8.31$ g plant $^{-1}$ and 10.54 g plant $^{-1}$ in Arrowhead plant, $4.13 \mathrm{~g} \mathrm{plant}^{-1}, 5.59 \mathrm{~g} \mathrm{plant}^{-1}$ and $7.26 \mathrm{~g} \mathrm{plant}^{-1}$ in Philodendron and $1.53 \mathrm{~g} \mathrm{plant}^{-1}, 3.04 \mathrm{~g} \mathrm{plant}^{-1}$ and $4.46 \mathrm{~g} \mathrm{plant}^{-1}$ in Boat lily) in all the three stages of observations. However, minimum root weight was observed in $\mathrm{T}_{1}$ (Irrigation water) for Devil's ivy at 30, 60 and 90 days of observations respectively. Eventually, the data on 60 and 90 days showed minimum root weight values under the treatment $\mathrm{T}_{4}$ (Saparamadu solution) at all the three stages of observations (Table 3).

The superiority of the treatment $\mathrm{T}_{3}$ (Cooper's solution) in producing more number of roots, lengthy roots and increased root weight may be due to the availability of nutrients which nourishes the root zone for better uptake of nutrients. The root density increases as new roots are produced. The regeneration of new roots is essential for normal plant development, as the majority of nutrients are absorbed through younger root tissues. Further, phosphorus and potassium are the two main nutrients that support root growth in plants. Specifically, they encourage plants to produce new roots and strengthen the existing roots. This means that nutrient solution was high in phosphorus and potassium formulations and this leads to production of more roots. In this present experiment, it is evident from the composition of Cooper's solution that, the increased phosphorous and potassium content might have influenced the mobilization and uptake of nutrients by the active roots produced in larger quantities by all the foliage ornamentals. Further, the increase in root number and length due to the presence of phosphorous which enhanced the permeability of root membrane stimulating the growth of roots and increasing the proliferation of root hairs. The results are in accordance with the findings of Kilinc et al. (2007) in oil palm seedlings and Li and Cheng (2014) in cucumber.

Looking on the minimum root obtained in the treatment $T_{1}$ (Irrigation water), it is clear that Devil's ivy is a hardy plant that can thrive well under minimal nutrition which also has the capability to absorb nutrition by roots. On the other hand, plants were grown under the treatment $\mathrm{T}_{4}$ (Saparamadu solution) produced the lowest root growth (number of roots, root length and weight of roots) during 60 and 90 days of observations in Wandering jew, Arrowhead plant, Philodendron and Boat lily. The composition of nutrients and the total ionic concentration determines the growth and development. The total ions were dissolved in the salt solution that exerts a force called osmotic pressure. Hence, Electrical conductivity (EC) of the solution is a good indicator of the amount of ions to the plants in the root zone (Nemali and Van Iersel, 2004). Sonneveld and Voogt (2009) suggested the optimal EC for hydroponic solution is 1.5 to $2.5 \mathrm{dS} \mathrm{m}^{-1}$. Higher EC hinders nutrient uptake through roots by increasing osmotic pressure (Samarakoon et al., 2006).

In the present investigation, it is evident from the (Fig.1) that the EC of the Saparamadu solution was gradually increased from

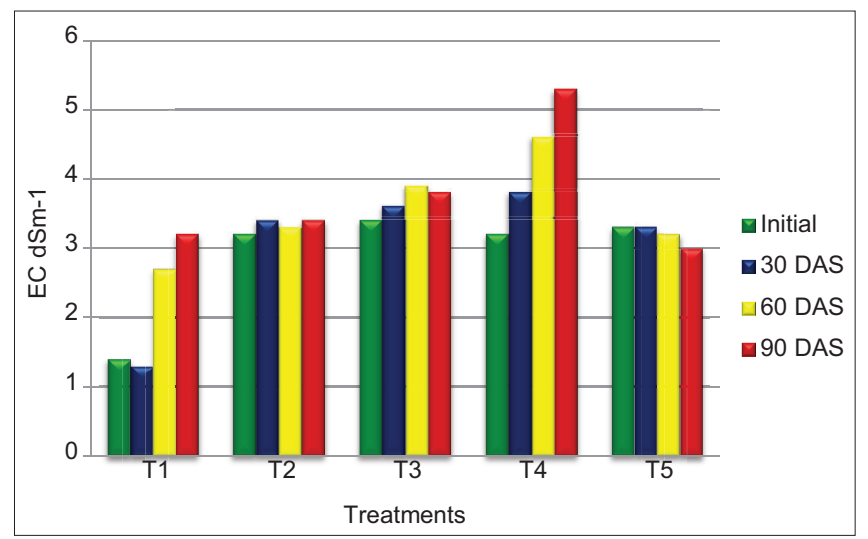

Figure 1: Effect of EC on performance of foliage ornamental plants in vertical passive hydroponics

$3.2 \mathrm{dS} \mathrm{m}^{-1}$ to $5.3 \mathrm{dS} \mathrm{m}^{-1}$ especially during 60 and 90 days. Hence, the reduced root growth were observed under Saparamadu solution $\left(\mathrm{T}_{4}\right)$ due to the improper relationship of mutual exchange ratio of anions: $\mathrm{NO}_{3}, \mathrm{H}_{2} \mathrm{PO}_{4}$ and $\mathrm{SO}_{4}$ and the mutual exchange of cations; $\mathrm{K}^{+}, \mathrm{Ca}^{2+}, \mathrm{Mg}^{2+}$ are reported to create a negative impact on root absorption and ultimately on plant growth as suggested by Tellez and Merino (2012). Further, nutrient availability for plant uptake at $\mathrm{pH}$ above 7 may be restricted due to precipitation of $\mathrm{Fe}^{2+}, \mathrm{Mn}^{2+}, \mathrm{PO}_{3}^{-4}, \mathrm{Ca}^{2+}$ and $\mathrm{Mg}^{2+}$ to insoluble and unavailable salts as reported by (Resh, 2004). Similar results are also obtained by Keat and Kannan (2015) in Chinese cabbage, Gruda (2009) and Chadirin et al. (2007) in soilless cultivation.

From the results it could be concluded that the root parameters viz., number of roots, root length and root weight exerted maximum values in those plants grown under $\mathrm{T}_{3}$ (Cooper's solution). Minimum rooting with lowest weight was recorded in $\mathrm{T}_{4}$ (Saparamadu solution) in all the stages of observation in devil's ivy. Whereas in other four ornamentals viz., Wandering jew (Zebrina pendula), Arrowhead plant (Syngonium podophyllum), Philodendron (Philodendron erubescens) and Boat lily (Tradescantia spathacea) recorded lowest root parameters in $T_{1}$ (Irrigation water) under 30 days of observation and at 60 and 90 days minimum number of roots, root length and root weight was recorded under $\mathrm{T}_{4}$ (Saparamadu solution).

\section{REFERENCES}

1. Chadirin, Y., Matsuoka,T., Suhardiyanto, H. and Susila,A.D. 2007. Application of deep sea water (DSW) for nutrient supplement in hydroponics cultivation of tomato: Effect of supplement DSW at different EC levels on fruit properties. Indonesian Journal of Agronomy, 35(2): 118-126.

2. Cooper, A. 1979. The ABC of NFT. Nutrient film technique. The world's first methods of crop production without a solid rooting medium. Grower books.

3. Gruda, N. 2009. Do soilless culture systems have an influence on product quality of vegtables? Journal of Applied Botany and Food Quality, 82: 141-147.

4. Hoagland, D. R. and Arnon, D 1938. Growing plants without soil by the water- culture method, Circ. California Agricultural Experimental Station, 347

5. Keat, C. K. and Kannan, C. 2015. Development of a cylindrical hydroponics system for vertical farming. Journal of Agricultural 
Science and Technology, 5: 93-100.

6. Kilinc, S. S., Ertan,E. and Seferglu,S. 2007. Effect of different nutrient solution formulations on morphological and biochemical characteristics of nursery fig tree grown in substrate culture. Scientific Horticulture, 113(1): 20-27.

7. Li, H. and Cheng, Z. 2014. Hoagland nutrient solution promotes the growth of cucumber seedling under light-emitting diode light. Acta Agri. Scandinavica, 65(1): 74-82.

8. Mattson, N. S. and Peters, C. 2014. A recipe for hydroponic success. http://www.greenhouse.corenell.edu/crops/factsheets/hydroponicrecipes.pdf p.16-19

9. Nemali, K. S. and Van lersel, M.W. 2004. Light Intensity and Fertilizer Concentration: I. Estimating Optimal Fertilizer Concentration from Water-Use Efficiency of Wax Begonia. Horticultural Science, 39(6):
1287-1292.

10. Resh, H. M. 2004. Hydroponic Food Production: A Definitive Guidebook for the Advanced Home Gardener and the Commercial Hydroponic Grower. CRC Press, New Jersey.

11. Samarakoon, U., Weerasinghe, P. and Weerakoddy, W. 2006. Effect of electrical conductivity (EC) of the nutrient solution on uptake, growth and yield of leaf lettuce (Lettuce sativa L.) in stationary culture. Tropopical Agricultural Research, V ol. 18.

12. Saparamadu, J. S., Wijesekera, R.D., Gunawardhana, H.D. and Weerakkody,W. 2010. A low cost nutrient formulation with a buffer for simplified hydroponics systems. Journal of Horticulture and Forestry, 2(5): 99-103.

13. Sonneveld, C. and Voogt, W. 2009. Nutrient management in substrate systems. Plant nutrition of green house crops. Springer, 277-312. 